\title{
EFEKTIFITAS PIJAT OKSITOSIN TERHADAP PENGELUARAN ASI DI RSIA ANNISA TAHUN 2017
}

\author{
Dewi Umbarsari \\ Akademi Kebidanan Jakarta Mitra Sejahtera Jambi \\ email: umbarsari_d@yahoo.com
}

\begin{abstract}
Abstrak
Pemberian ASI Ekslusif di Indonesia menurut data Riset Kesehatan Dasar tahun 2013 hanya mencapai angka 30,2\%, sementara itu target pemberian ASI ekslusif di Indonesia harus mencapai 80\%. Penyebab rendahnya pemberian ASI Ekslusif adalah penurunan produksi ASI yang disebabkan oleh kurangnya rangsangan hormone oksitosin dan prolactin. Pijat Oksitosin sangat membantu dalam proses pengeluaran ASI. Penelitian ini bertujuan untuk mengetahui efektifitas pijat oksitosin terhadap pengeluaran ASI di RSIA Annisa tahun 2017.Jenis penelitian yang digunakan adalah Quasy Experiment dengan rancangan yang digunakan post test only design with control group. Penelitian dilaksanakan selama 25 hari pada tanggal 4-28 April 2017 di RSIA Annisa Jambi. Populasi penelitian adalah ibu post partum 3 jam. Teknik Pengambilan sampel dengan non probability sampling dengan 12 responden kelompok perlakuan dan 12 responden kelompok kontrol. Hasil penelitian dapat disimpulkan bahwa rerata waktu pengeluaran ASI kelompok perlakuan 5.15 jam sedangkan rerata waktu pengeluaran ASI kelompok kontrol $8.30 \mathrm{jam}$. Hasil uji T-Test Independent nilai $p$-value $=0.006$ yang berarti $p<0.05$ menyatakan ada pengaruh pijat oksitosin terhadap rerata waktu pengeluaran ASI.Setiap petugas kesehatan khususnya Bidan hendaknya dapat mengaplikasikan pijat oksitosin kepada ibu postpartum agar ibu dapat tetap memberikan ASI pada bayi segera setelah lahir.
\end{abstract}

Kata kunci : pijat oksitosin, pengeluaran ASI

\begin{abstract}
According to the data of Health Researchin 2013 only 30,2\%, while the target of exclusive breastfeeding in Indonesia have to reach $80 \%$. The low breastfeeding because decrease mother's milk production less by the luck of stimulation of the oxytocin and prolactin hormone. Massage oxytocin very helpful in processing to get the milk.The purpose of research to determine the effect of oxytocin massage to Breastfeeding in RSIA Annisa 2017. This type of research is quasy experiment with design post test only control group design. The research was conducted 25 days on 4-28 April 2017 in RSIA Annisa Jambi. The Population in this research was postpartum 3 hours. The sampling tecnik with non probability sampling with 12 respondent group of treatment and 12 respondent group of the control.The results of research can be concluded that treatment group meanbreastfeeding time 5:15 hours, while the control group mean breastfeeding time 8:30 hours. The test results independent Ttest $p$-value $=0,006$ which means $p<0,05$, the oxytocin messege effect on the everage time breastfeeding.Midwife or public health have to apply massage oxytocin to the mother postpartum to give breast milk on her baby after birth.
\end{abstract}

Keywords : oksitosin massage, breastfeeding

\section{PENDAHULUAN}

World Health Organization (WHO) tahun 2006 dalam Roesli 2010, mengeluarkan Standar Pertumbuhan Anak yang kemudian diterapkan di seluruh dunia, isinya menegaskan pentingnya pemberian ASI saja kepada bayi sejak lahir sampai usia 6 (enam) bulan. Setelah itu, bayi baru boleh diberikan makanan pendamping ASI sambil tetap diberi ASI hingga usianya mencapai 2 tahun. Dengan 
adanya peraturan yang ditetapkan WHO tersebut, di Indonesia juga menerapkan peraturan terkait pentingnya ASI Ekslusif dengan cara mengeluarkan Peraturan Pemerintah (PP) no 33/2012 tentang Pemberian ASI Ekslusif. Peraturan ini menyatakan kewajiban ibu untuk menyusui bayinya sejak lahir sampai bayi berusia 6 bulan (AIMI, 2014).

Selain itu pentingnya ASI juga terlihat pada acara dunia yaitu Pekan ASI sedunia Agustus 2008, The World Alliance For Breast Feeding Action (WABA) memilih tema Mother Support: Going For the Gold. Makna tema tersebut adalah suatu gerakan untuk mengajak semua orang meningkatkan dukungan kepada ibu untuk memberikan bayibayi mereka makanan yang berstandar emas yaitu ASI yang diberikan eksklusif selama 6 bulan pertama dan melanjutkan ASI bersama makanan pendamping ASI lainnya yang sesuai sampai bayi berusia 2 tahun atau lebih.

ASI Eksklusif merupakan makanan pertama, utama dan terbaik bagi bayi, yang bersifat alamiah. ASI mengandung berbagai zat gizi yang dibutuhkan dalam proses pertumbuhan dan perkembangan bayi (Kodrat, 2010). Khasiat ASI begitu besar seperti ASI dapat menurunkan risiko bayi mengidap berbagai penyakit. Apabila bayi sakit akan lebih cepat sembuh bila mendapatkan ASI. ASI juga membantu pertumbuhan dan perkembangan kecerdasan anak.

Tidak sedikit ibu yang kecewa karena ternyata ASI yang keluar tidak selancar seperti yang diharapkan, para ibu lebih memilih untuk memberikan anak nya susu formula. Pengeluaran hormon oksitosin selain dipengaruh oleh isapan bayi juga dipengaruhi oleh reseptor yang terletak pada sistem duktus, bila duktus melebar atau menjadi lunak maka secara reflektoris dikeluarkan oksitosin oleh hipofise yang berperan untuk memeras air susu dari alveoli (Endah, 2011).

$$
\text { Diperlukan adanya upaya }
$$

mengeluarkan ASI untuk beberapa ibu postpartum. Dalam upaya tersebut ada 2 hal yang mempengaruhi yaitu produksi dan pengeluaran. Produksi ASI dipengaruhi oleh hormon prolaktin sedangkan pengeluaran dipengaruhi oleh hormon oksitosin . Hormon oksitosin akan keluar melalui rangsangan ke puting susu melalui isapan mulut bayi atau melalui pijatan pada tulang belakang ibu bayi, dengan dilakukan pijatan pada tulang belakang, ibu akan merasa tenang, rileks, meningkatkan ambang rasa nyeri dan mencintai bayinya, sehingga dengan begitu hormon oksitosin keluar dan ASI pun cepat keluar (Endah, 2011).

Melalui pijatan atau rangsangan pada tulang belakang, neurotransmitter akan merangsang medulla oblongata langsung mengirim pesan ke hypothalamus di hypofise posterior untuk mengeluarkan oksitosin sehingga menyebabkan payudara mengeluarkan air susu. Dengan pijatan didaerah tulang belakang ini juga akan merileksasi ketegangan dan menghilangkan stress dan dengan begitu hormon oksitosoin keluar sehingga akan membantu pengeluaran ASI, dibantu dengan isapan bayi pada puting susu pada saat segera setelah bayi lahir dengan keadaan bayi normal (Perinasia, 2007).

Pijat oksitosin dilakukan pada ibu setelah melahirkan untuk membantu kerja hormon oksitosin dalam pengeluaran ASI, mempercepat syaraf parasimpatis menyampaikan sinyal ke otak bagian belakang untuk merangsang kerja oksitosin dalam mengalirkan ASI agar keluar. Tindakan massage dapat mempengaruhi hormone prolactin yang berfungsi sebagai stimulus produksi ASI pada ibu selama menyusui. Tindakan ini juga dapat membuat rileks pada ibu dan melancarkan aliran syaraf serta saluran ASI pada kedua payudara (Khasanah, 2010).

Studi pedahuluan dilakukan di RSIA Annisa Jambi dengan wawancara kepada petugas kesehatan di ruang perawatan lantai II dan III. Studi Pendahuluan ini dilakukan pada bulan Maret 2017, didapatkan hasil bahwa bayi - bayi denganlahir normal dilakukan Inisiasi Menyusu Dini (IMD) lalu dibersihkan atau dimandikan kemudian diberikan lagi kepada ibu postpartum untuk kemudian disusui. Ibu melahirkan dengan tindakan Sectio Caesarea bayi diberikan ke ibunya setelah ibu pulih dan masuk ke ruang perawatan.

Setelah beberapa jam bayi rawat gabung dengan ibunya diruang perawatan, akhinya ibu postpartum mengembalikan bayinya ke ruang perinatologi dengan alasan bahwa bayi menangis dan ASI belum keluar dan ibu postpartum ingin istirahat karena merasa sakit pada luka perineum atau luka bekas operasi Sectio Caesarea. Sebagian ibu postpartum dan keluarga menganggap bahwa untuk memberikan ASI payudaranya harus 
ditunggu sampai penuh atau keras, agar keluarnya kental dan banyak, sehingga banyak ibu-ibu postpartum mengalami pembengkakan pada payudara atau terjadi mastitis yang diakibatkan terlambat memberikan ASI. Hal ini disebabkan oleh ketidaktahuan ibu postpartum atau keluarga tentang bagaimana usaha-usaha untuk mengeluarkan ASI dan tidak adanya tenaga kesehatan yang memberi bantuan pada ibu di saat ibu memerlukannya atau disebabkan layanan kesehatan dan sarana yang ia terima dari petugas kesehatan tidak mendukung proses menyusui.

Tujuan penelitian ini adalah untuk mempelajari efektifitas pijat oksitosin terhadap pengeluaranASI di RSIA Annisa Jambi.

\section{METODE PENELITIAN}

Desain penelitian ini adalah quasi eksperiment dengan rancangan One Group pre and post test design yaitu observasi dilakukan sebelum dan sesudah diberikan perlakuan pada responden.

Penelitian dilakukan di ruang perawatan lantai II dan III RSIA Annisa Jambi tanggal 4-28 April 2017. Populasi dalam penelitian ini adalah Ibu post partum 3 jam yang diberikan perlakuan yaitu pijat oksitosin. Sedangkan populasi kontrol dalam penelitian ini adalah seluruh ibu postpartum yang tidak diberi perlakuan pijat oksitosin.

Pengambilan sampel dilakukan dengan cara Non Probability Sampling-Purpossive
Sampling Type dengan 12 responden kelompok perlakuan dan 12 responden kelompok kontrol.Selanjutnya peneliti melakukan pijat oksitosin pada responden yang diberikan perlakuan 3 jam setelah melahirkan kemudian dilakukan pemijatan selama 20 menit menggunakan baby oil pada bagian leher dan bahu guna merilekskan tubuh lalu dilanjutkan dari bagian pinggang belakang menyusuri tulang belakang sampai dengan scapula membentuk huruf "V", kemudian diukur waktu pengeluaran ASI menggunakan Jam.

Selanjutnya dilakukan observasi dan pengukuran pada kedua kelompok yang diberikan perlakuan serta yang tidak diberikan perlakuan.Waktu pengeluaran ASI dimasukkan kedalam lembar observasi.

Analisis data dengan univariat dan bivariat untuk melihat efektifitas hubungan antar variabel bebas (pijat oksitosin) dengan variabel terikat Pengeluaran ASI), uji statistikmenggunakan t-test dependent dengan tingkat signifikan 0,05 (Notoadmojo, 2010).

\section{HASIL DAN PEMBAHASAN}

Berdasarkan penelitian yang dilakukan peneliti di RSIA Annisa Kota Jambi pada tanggal 4-28 April 2017 didapatkan hasil sebagai berikut:

Tabel 1. Distribusi Karakteristik Rerata Waktu Pengeluaran ASI Pada Ibu Postpartum

\begin{tabular}{cccc}
\hline Kelompok Perlakuan & Mean (Jam) & Varians & $\mathrm{N}$ \\
\hline $\begin{array}{c}\text { Pengeluaran ASI dengan dilakukan pijat } \\
\text { Oksitosin }\end{array}$ & 5.15 & 0,341 & 12 \\
$\begin{array}{c}\text { Pengeluaran ASI yang tidak dilakukan pijat } \\
\text { Oksitosin }\end{array}$ & 8.30 & 5,477 & 12 \\
\hline
\end{tabular}

Tabel 1 menunjukkan rerata waktu pengeluaran ASI pada ibu postpartum yang dilakukan pijat oksitosin yaitu selama 5.15 jam. Sedangkan rerata waktu pengeluaran ASI pada ibu postpartum yang tidak dilakukan pijat oksitosin yaitu selama 8.30 jam.

Hasil penelitian ini menunjukkan pada kelompok perlakuan rerata waktu pengeluaran ASI 5.15 jam. Pijat oksitosin dilakukan berdasarkan SOP yang diberikan pada ibu postpartum. Sedangkan hasil yang diperoleh pada kelompok yang tidak dilakukan pijat oksitosin (kontrol) rerata waktu pengeluaran ASI yaitu $8.30 \mathrm{Jam}$.

Pengeluaran ASI dapat dipercepat dengan tindakan non farmakologis yaitu melalui pijatan atau rangsangan pada tulang belakang, neurotransmitter akan merangsang medulla oblongata langsung mengirim pesan ke hypothalamus di hypofise posterior untuk mengeluarkan oksitosin yang menyebabkan payudara mengeluarkan ASI. Dengan pijatan di daerah tulang belakang ini juga akan merelaksasi ketegangan dan menghilangkan stress, dengan begitu hormone oksitosin keluar 
dan akan membantu pengeluaran ASI, dibantu dengan isapan bayi pada puting susu sesaat segera setelah bayi lahir, ASI yang menetes atau keluar merupakan tanda aktifnya reflek oksitosin (Perinasia, 2007).

Hasil penelitian ini relevan dengan hasil penelitian Endah (2011), yang mendapatkan waktu pengeluaran kolostrum kelompok perlakuan rata-rata 5.8 jam.

Salah satu teori persalinan adalah adanya hormon estrogen dan progesteron turun secara drastis sehingga digantikan oleh hormon prolaktin dan hormon oksitosin. Hormon prolaktin dan oksitosin memainkan peran dalam proses laktasi sehingga pengeluaran ASI akan lancar. ASI yang tidak keluar bukan karena produksi ASI yang tidak tercukupi, tetapi produksi ASI cukup namun pengeluarannya terhambat akibat hambatan sekresi oksitosin (Guyton \& Hall, 2007).

Hal ini menunjukkan kesesuaian dengan teori, bahwa pijat oksitosin yang dilakukan di sepanjang tulang belakang (vertebrae) sampai tulang costae kelimakeenam akan merangsang hormon prolactin yang diproduksi oleh hypofise anterior dan oksitosin yang diproduksi oleh hypofise posterior sehingga ASI otomatis dapat lebih lancar. Selain memperlancar ASI, pijat oksitosin memberikan kenyamanan pada ibu postpartum, mengurangi bengkak (engorgement), mengurangi sumbatan ASI, merangsang pelepasan hormon oksitosin, mempertahankan produksi ASI ketika ibu dan bayi sakit. Adanya rasa nyaman yang dirasakan ibu selama pemijatan merupakan syarat keberhasilan pijat oksitosin (Roesli, 2010).

ASI keluar dari hari pertama $(<24$ jam $)$ setelah melahirkan. Hal ini menunjukkan kesesuaian hasil penelitian dengan teori. Jika tidak dilakukan pijat oksitosin pengeluaran ASI terjadi keterlambatan dibanding dengan ibu yang dilakukan pijat oksitosin. Ibu yang tidak dilakukan pijat oksitosin mengalami keterlambatan pengeluaran ASI, hal ini bisa terjadi karena puting susu ibu yang sangat kecil karena akan membuat produksi hormon oksitosin dan hormon prolaktin akan terus menurun dan ASI akan terhenti. Selain itu produksi ASI sangat dipengaruhi oleh faktor kejiwaan, ibu yang selalu dalam keadaan tertekan, sedih, kurang percaya diri dan berbagai bentuk ketegangan emosional akan menurunkan volume ASI bahkan tidak akan terjadi produksi ASI. ASI dapat diproduksi dengan baik jika ibu dalam keadaan tenang dan nyaman (Varney, 2008).

Tabel 2. Normalitas Distribusi Kelompok Perlakuan Dan Kelompok Kontrol

\begin{tabular}{lccc}
\hline \multicolumn{4}{c}{ Test Of Normality } \\
\hline \multirow{2}{*}{ Kelompok } & \multicolumn{3}{c}{ Shapiro-Wilk } \\
\cline { 2 - 4 } & Statistik & Df & Sig \\
\hline Perlakuan & 0.862 & 12 & 0.380 \\
Kontrol & 0.803 & 12 & 0.127 \\
\hline \multicolumn{4}{c}{$\alpha=0.05$} \\
\hline
\end{tabular}

Berdasarkan hasil uji normalitas varians dengan menggunakan uji Shapiro Wilk, nilai signifikan untuk kelompok perlakuan 0.380 dan kelompok kontrol 0.127. Karena nilai signifikan kedua kelompok lebih dari 0.05 maka dapat dikatakan bahwa kelompok kontrol dan kelompok perlakuan berdistribusi normal.

Analisis bivariat dilakukan dengan uji $T$-Test Independent untuk membandingkan dua kelompok mean dari dua sampel yang berbeda. Prinsipnya ingin mengetahui apakah ada perbedaan efektifitas mean antara dua sampel, dengan tingkat kepercayaan $95 \%$ atau taraf signifikan $\alpha=0.05$, apabila nilai $p$ value $<0.05$ berarti terdapat pengaruh yang signifikan antara variabel independen dan variabel dependen. 
Tabel 3. Perbedaan Rerata Waktu Pengeluaran ASI Pada Kelompok Perlakuan dan Kelompok Kontrol

\begin{tabular}{cccc}
\hline Kelompok & Mean $(\mathrm{Jam})$ & p-value & $\mathrm{N}$ \\
\hline Perlakuan & 5.15 & \multirow{2}{*}{0.006} & 12 \\
Kontrol & 8.30 & & 12 \\
\hline & $\alpha=0.05$ & \\
\hline
\end{tabular}

Berdasarkan tabel 3 diketahui bahwa pada kelompok perlakuan rerata waktu pengeluaran ASI 5.15 jam, sedangkan pada kelompok kontrol 8.30 jam. Hasil uji statistik didapatkan $p$-value $=0.006(\mathrm{p}<0.05)$ artinya ada pengaruh efektifitas pijat oksitosin terhadap rerata pengeluaran ASI.

Hasil perhitungan dengan analisa statistik T-Test Independent pada 12 responden kelompok perlakuan dan 12 responden kelompok kontrol didapatkan nilai $\mathrm{p}=0.006$ $(<0.05)$ yang dapat disimpulkan bahwa terdapat pengaruh rerata waktu pengeluaran ASI antara kelompok perlakuan dan kelompok kontrol. Hasil tersebut menunjukkan terdapat perbedaan waktu lama pengeluaran ASI antara ibu postpartum yang dilakukan pijat oksitosin (perlakuan) dengan ibu yang tidak dilakukan pijat oksitosin (kontrol). Pijat oksitosin yaitu suatu cara untuk membantu mempercepat pengeluaran ASI dengan cara memberikan rangsangan pijat pada kedua sisi tulang belakang, mulai dari leher ke arah tulang belikat dilanjutkan ke tulang costae ibu postpartum (Perinasia, 2007).

Melalui rangsangan atau pijatan pada tulang belakang, neurotransmitter akan merangsang medullaoblongata langsung mengirim pesan ke hypothalamus di hypofise posterior untuk mengeluarkan oksitosin yang menyebabkan payudara mengeluarkan ASI. Dengan pijatan di daerah tulang belakang ini juga akan memberi rasa rileks, menghilangkan stress dan dengan begitu hormon oksitosin keluar dan akan membantu pengeluaran ASI. ASI yang menetes atau keluar merupakan tanda aktifnya reflex oxytocin (Perinasia, 2007).

Pada kenyataannya menyusui bukanlah suatu aktivitas yang terjadi secara otomatis, hal tersebut membutuhkan hal-hal yang dapatmemotivasi dan merubah cara pandang ibu mengenai menyusui seperti beberapa penelitian yang dilakukan oleh Amin tahun
2011 menyatakan bahwa pengetahuan serta keterampilan ibu mempengaruhi kepercayaan diri ibu dalam menyusui. Kurang lancarnya pengeluaran ASI setelah kelahiran perlu ditanggapi karena hal ini akan mempengaruhi pemberian ASI ekslusif oleh ibu.

Penelitian oleh Ummah tahun 2014 massage/pijat merupakan salah satu terapi pendukung yang efektif untuk mengurangi ketidaknyamanan fisik serta memperbaiki gangguan mood. Pengurangan ketidaknyamanan pada ibu menyusui akan membantu lancarnya pengeluaran ASI. Terjadinya peningkatan produksi ASI pada kelompok perlakuan dapat memberikan efek rileks pada ibu yang secara tidak langsung dapat menstimulasi hormone oksitosin yang dapat membantu proses kelancaran produksi ASI. Penelitian Gustriani tahun 2015 menyatakan bahwa pada kelompok bayi yang hanya menerima ASI, maka ASI pertama/kolostrum akan keluar 23 jam pasca melahirkan.

Stimulasi oksitosin membuat sel-sel mioepitel di sekitar alveoli di dalam kelenjar payudara berkontraksi. Kontraksi sel-sel menyebabkan ASI keluar melalui duktus dan masuk ke dalam sinus-sinus laktiferus. Refleks let-down dapat dirasakan sebagai sensasi kesemutan atau dapat juga ibu tidak merasakan sensasi apapun. Tanda-tanda lain let-down adalah tetesan ASI dari payudara ibu dan ASI menetes dari payudara lain yang tidak sedang diisap oleh bayi (Kodrat, 2010).

Dalam penelitian ini kelompok perlakuan rerata waktu pengeluaran ASI 5.15 jam lebih singkat dari rerata kelompok kontrol 8.30 jam. Hal tersebut menunjukkan kesesuaian dengan teori, dengan melakukan pemijatan pada sepanjang tulang belakang (vertebrae) sampai tulang costae kelimakeenam akan merangsang hormon prolaktin yang dikeluarkan oleh hipofise anterior dan hormon oksitosin yang dikeluarkan oleh 
hipofise posterior, sehingga ASI keluar yang terjadi karena sel otot halus di sekitar kelenjar payudara mengerut. Penyebab otot-otot itu mengerut adalah hormon oksitosin (Kodrat, 2010).

Selain memperlancar ASI, pijat oksitosin memberikan kenyamanan pada ibu nifas, mengurangi bengkak (engorgement), mengurangi sumbatan ASI, merangsang pelepasan hormon oksitosin, mempertahankan produksi ASI ketika ibu dan bayi sakit. Adanya rasa nyaman yang dirasakan oleh ibu selama proses pemijatan merupakan syarat keberhasilan pijat oksitosin (Roesli, 2010).

Faktor-faktor yang meningkatkan let down reflex adalah: melihat bayi, mendengarkan suara bayi, mencium bayi, memikirkan untuk menyusui bayi, memijat tulang belakang (pijat oxytocin). Sedangkan faktor-faktor yang menghambat let down reflex adalah stress seperti: keadaan bingung atau pikiran kacau, takut, dan cemas.

Bila ada stress dari ibu yang menyusui maka akan terjadi suatu blockade dari let down reflex, ini disebabkan oleh karena adanya pelepasan dari adrenalin epineprin yang menyebabkan vasokonstriksi dari pembuluh darah alveoli, sehingga oksitosin sedikit harapannya untuk dapat mencapai target organ mioepithelium. Akibat dari tidak sempurnanya let down reflex maka akanterjadi penumpukan ASI di dalam alveoli yang secara klinis tampak payudara membesar.

Payudara yang membesar akan berakibat abses, gagal untuk menyusui dan rasa sakit. Rasa sakit ini akan merupakan stress lagi bagi seorang ibu sehingga stress akan bertambah. Karena let down reflex tidak sempurna maka bayi yang haus jadi tidak puas. Ketidakpuasan ini akan menyebabkan tambahan stress bagi ibunya. Bayi yang haus dan tidak puas ini akan berusaha untuk mendapatkan air susu yang cukup dengan cara menambah kuat isapannya sehingga tidak jarang dapat menimbulkan luka-luka pada puting susu, luka-luka ini akan dirasakan sakit oleh ibunya yang juga akan menambah stresnya tadi. Dengan demikian akan terbentuk satu lagi lingkaran setan yang tertutup (circulusvitiosus) dengan akibat kegagalan dalam menyusui.

\section{KESIMPULAN DAN SARAN}

Berdasarkan hasil analisis dan pembahasan dapat disimpulkan bahwa:

1. Rerata waktu pengeluaran kolostrum pada ibu post partum kelompok perlakuan pijat oksitosin adalah 5.15 jam.

2. Rerata waktu pengeluaran kolostrum pada ibu post partum kelompok kontrol 8.30 jam.

3. Pijat oksitosin berpengaruh terhadap rerata pengeluaran kolostrum pada ibu post partum ( $p$-value $=0.006)$.

Saran dari hasil penelitian ini yaitu setiap petugas kesehatan khususnya bidan yang menemukan kejadian bahwa ASI tidak keluar maka hendaknya bidan memberikan tindakan kepada klien untuk dilakukan pijat oksitosin selain itu tenaga kesehatan juga dapat memberikan pendidikan kesehatan kepada ibu dan keluarga untuk tetap memberikan ASI pada bayi di awal kehidupannya.

\section{REFERENSI}

AIMI. 2014. Profil Kesehatan Ibu dan Anak. Jambi.

Amin M, Rehana, Jaya H. 2011. Efektifitas Massage Rolling (Punggung) Terhadap Produksi ASI Pada Ibu Post Sectio Caesarea di RS Muhammadiyah Palembang. Jurnal Keperawatan. Vol.IX. No.VII. Hal: 13-20.

Endah, S.N.\& Masdinarsah, I. 2011. Pengaruh pijat oksitosin terhadap pengeluaran kolostrum pada ibu post partum di ruang kebidanan Rumah Sakit Muhammadiyah Bandung. Jurnal Kesehatan Kartika. Vol. 02. No. XIX. Hal: 90-99.

Gustriani, N. 2015. Pengaruh Pijat Oksitosin terhadap Pengeluaran ASI pada Pasien Post Sectio Caesarea di Ruangan Nifas Rumah Sakit Wilayah Makassar. Tesis Program Pasca Sarjana Kebidanan. Unhas.

Guyton \& Hall. 2007. Buku Ajar Fisiologi Kedokteran. Edisi II. Jakarta: EGC.

Khasanah, Nur. 2010. ASI atau Susu Formula. Yogyakarta: Flashbook.

Kodrat, Laksono. 2010. Dahsyatnya ASI dan Laktasi. Yogyakarta: Media Baca. 
Notoatmodjo, S. 2010. Metodologi Penelitian Kesehatan. Jakarta: PT Rineka Cipta.

Perinasia, 2007.Manajemen Laktasi. Jakarta : Gramedia.

Roesli, U. 2010. Inisiasi Menyusu Dini Plus ASI Ekslusif. Jakarta: Pustaka Bunda.

Ummah, Faizatul. 2014. Pijat Oksitosin untuk Mempercepat Pengeluaran ASI pada Ibu Pasca Salin Normal di Dusun
Sono Desa Ketanen Kecamatan Panceng Gresik.Jurnal Surya. Vol.XI, No.70. Hal:49-56.

Varney, Helen., Kriebs, Jan M., Gegor C.L. 2008. Buku Ajar Asuhan Kebidanan.Edisi 4 Volume 2. Jakarta: EGC. 